\title{
Understanding Pulmonary Stress-Strain Relationships in Severe ARDS and Its Implications for Designing a Safer Approach to Setting the Ventilator
}

\author{
Rolf D Hubmayr MD and Richard H Kallet MSc RRT FAARC
}

\author{
Introduction \\ Stress and Strain in the Respiratory System \\ Hooke's Law \\ How Strain-Stress Informs the Interpretation of Clinical Trials and Recent \\ Hypotheses of Ventilator-Induced Lung Injury \\ VILI, Biotrauma, and the Role of PEEP \\ Clinical Management Strategies \\ Maximum Lung Stress and $\mathbf{P}_{\text {plat }}$ \\ Unresolved Issues Surrounding VILI \\ Practical Bedside Strategy for Implementing Lung-Protective Ventilation \\ in Severe ARDS
}

\begin{abstract}
This review describes the current understanding of the lungs' response to deforming stress under conditions of both normal physiology and acute lung injury. Several limiting assumptions are needed to infer lung parenchymal stress and strain from airway pressure, volume, and flow data from mechanically ventilated patients with injured lungs. These assumptions include the effects of the chest wall on lung-surface pressure, its topographical distribution, and the effects of nonuniform tissue properties on local parenchymal stresses. In addition, there is a spectrum of biophysical lung injury mechanisms that involves normal as well as tangential alveolar wall stresses. To these are added important secondary effects on pulmonary vascular resistance and right heart function. Understanding both the assumptions of lung mechanics and the scope of injury mechanisms operating during ARDS is necessary to interpret the results of clinical trials that inform prevailing ventilator-management guidelines. The implications issuing from these 3 topics inform a safer approach to setting and adjusting the ventilator to minimize the risk of ventilator-induced lung injury. This is enumerated in a 5-step approach that can be used to guide ventilator management of unstable patients with severe lung injury. Key words: driving pressure; peep; plateau pressure ventilator-induced lung injury. [Respir Care 2018;63(2):219-226. (C) 2018 Daedalus Enterprises]
\end{abstract}

\section{Introduction}

The objective of this review is to put forth an approach to safer mechanical ventilation based on an understanding of factors that influence lung parenchymal stress and strain in disease. To this end, the limiting assumptions needed to infer lung parenchymal stress and strain from airway pressure, volume, and flow data of mechanically ventilated patients will be detailed, and the spectrum of biophysical lung injury mechanisms will be discussed. This knowledge will not only guide the interpretation of clinical trials, which to date have informed prevailing ventilator-management guidelines, but will also serve as the rationale for a 5-step outline for how clinicians may approach the management of unstable patients with severely injured lungs.

Stress and Strain in the Respiratory System

All modes of ventilator assistance share a common goal, namely, to support gas exchange while keeping lung pa- 


\section{Understanding Pulmonary Stress-Strain in ARDS}

renchymal stress within tolerance limits. Stress defines a force per unit area, and as such has the same unit of measure as pressure. The pressure that most closely correlates with lung parenchymal stress is the elastic recoil pressure of the lung, which in a uniformly expanded lung is equal to the pressure difference between the alveoli and the lung surface (ie, the visceral pleura). ${ }^{1}$

While all prevailing ventilator-management guidelines seek to minimize parenchymal stress, lung stress is typically inferred because it is difficult to measure in situ for 3 reasons. First, the lung is non-uniformly expanded in the intact thorax, resulting in non-uniform pleural pressure and thus non-uniform parenchymal stress distributions. ${ }^{2}$ While esophageal manometry may succeed in identifying patients with very high regional pleural pressures, it would be misleading to extrapolate lung stress remote from the measurement site. ${ }^{3}$

Second, in injured lungs a significant number of alveoli are not in communication with the central airways, either because they are filled with fluid or occluded by liquid bridges and mucus at the level of conducting airways and alveolar ducts. In that instance, alveolar pressure, and thus local stress of closed units, cannot be inferred from airway occlusion pressure measurements.

Third, in a diseased lung there are stress concentrations between regions with heterogeneous mechanical properties. This network property was first described by Mead et $\mathrm{al}^{4}$ under the heading of parenchymal interdependence, and it reflects the tissue distortion between structures that resist deformation (eg, a flooded or collapsed alveolus) and their more pliable neighbors (neighboring alveolar walls) (Fig. 1).

While parenchymal stress is an important determinant of injury risk, it is by no means the only one. Stress amplitude and its rate of change also shape the response of the lung to deforming stress. ${ }^{5}$ The importance of clinical ventilation parameters such as plateau pressure $\left(\mathrm{P}_{\text {plat }}\right)$, driving pressure $\left(\mathrm{P}_{\text {plat }}-\mathrm{PEEP}\right)$, tidal volume $\left(\mathrm{V}_{\mathrm{T}}\right)$, inspiratory flow, and breathing frequency can only be understood in

Dr Hubmayr is affiliated with the Pulmonary and Critical Care Medicine Division, Department of Internal Medicine, Mayo Clinic, Rochester, MN. Mr Kallet is affiliated with Respiratory Care Services, Department of Anesthesia and Perioperative Care, University of California, San Francisco at Zuckerberg San Francisco General Hospital, San Francisco, CA.

Dr Hubmayr discloses relationships with Philips Research North America and Global Blood Therapeutics. Mr Kallet discloses relationships with Nihon Kohden, Getinge Group USA, and Philips Respironics.

Correspondence: Richard H Kallet MSc RRT FAARC, Department of Anesthesia and Perioperative Care, University of California, San Francisco at Zuckerberg San Francisco General Hospital, Building 5:GA-2, 1001 Potrero Ave, San Francisco, CA 94110. E-mail: rich.kallet@ucsf.edu.

DOI: $10.4187 /$ respcare. 05900

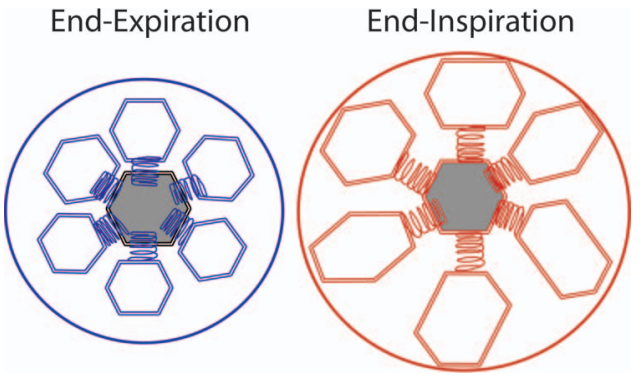

Fig. 1. Representation of shear stress developing within patent alveoli sharing common walls with a collapsed or non-expanding alveolus.

that context (Fig. 2). Driving pressure is analogous to stress amplitude, ie, the change in stress (or pressure) applied to a structure relative to its pre-stressed baseline state. A post hoc analysis of data from several large clinical trials suggested that driving pressure was the one variable that best stratified the biophysical lung injury risk of subjects with ARDS. ${ }^{6}$

For the purpose of that analysis, driving pressure was defined as the difference between extrinsic PEEP as set by the provider (assuming absence of inadvertent PEEP) and the end-inspiratory airway occlusion (ie, $\mathrm{P}_{\mathrm{plat}}$ ). This definition first discounts dynamic (loss) components of stress attributable to the rate of deformation, and second includes elastic pressures (stored energy) attributable to the elastic deformation of the passive chest wall. Therefore, it is best to refer to it as static respiratory system driving pressure or $\Delta \mathrm{P}$. These limiting assumptions should not distract from the importance of the observation by Amato et $\mathrm{al}^{6}$ insofar as it suggests that between-patient variability in chest-wall mechanics and dynamic energy dissipation may play a lesser role as injury risk factors.

While there is sound theoretical and some experimental evidence that the rate and frequency of lung deformation (ie, flow and frequency settings) modify injury risk, there are few if any compelling human data on that subject. ${ }^{7}$ The rationale to limit ventilator frequency settings to $\leq 30-35$ cycles/min is largely based on diminishing rate effects on alveolar ventilation, while the practice to impose decelerating as opposed to square wave flow profiles is largely guided by concerns for high peak airway pressures and theoretical predictions about regional ventilation distributions.

\section{Hooke's Law}

As defined by Hooke's law, stress amplitude varies with the amplitude of deformation and with the material properties of the deformed elastic object. The amplitude of the deformation is commonly expressed as strain. Engineers commonly define strain as a dimensionless ratio (ie, the 


\section{Understanding Pulmonary Stress-Strain in ARDS}

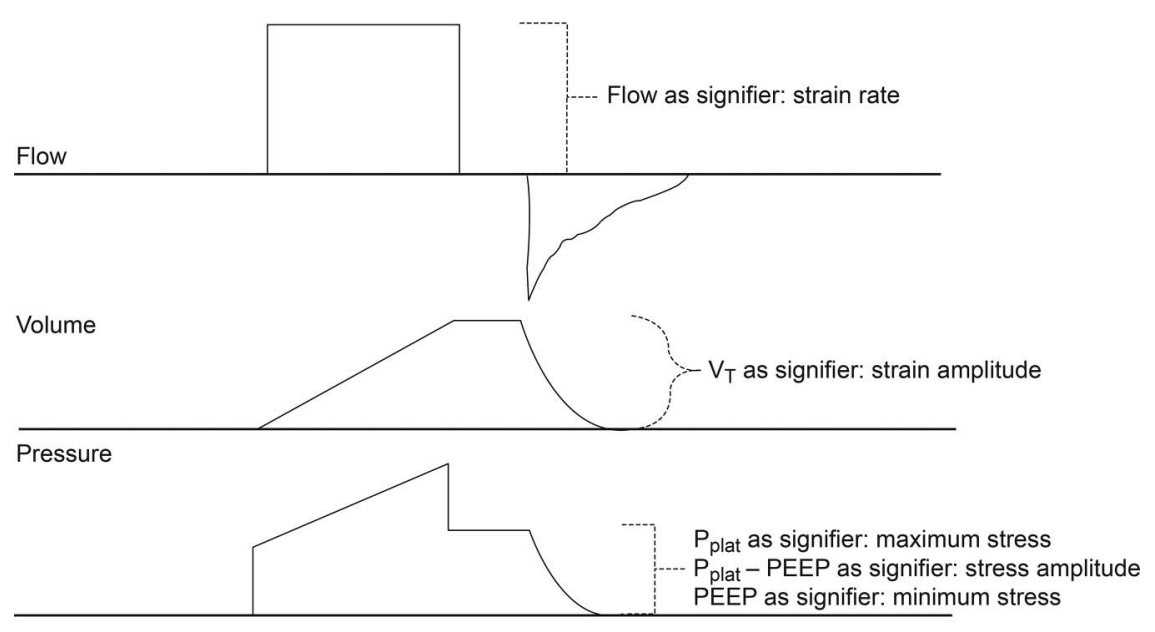

Time

Fig. 2. Common clinical measurements and their biophysical correlates. $V_{\mathrm{T}}=$ tidal volume, Pplat $=$ plateau pressure.

change in length or volume of a material relative to its unstressed and therefore un-deformed state). However, this definition is not useful in respiratory mechanics because the lung is pre-stressed in situ (ie, exposed to pleural pressure) so that its unstressed volume cannot be known. One may of course deviate from the engineering definition and normalize deformation (ie, $\mathrm{V}_{\mathrm{T}}$ ) by either the volume at end-expiration, or any other volume, such as the volume at zero airway pressure or total lung capacity for that matter. ${ }^{8-10}$

Needless to say, attempts to define unique strain injury thresholds suffer from this limitation and should be interpreted with caution. The biophysical injury mechanisms associated with large volume oscillations (ie, $\mathrm{V}_{\mathrm{T}}$ ), high end-inspiratory volumes, and low end-expiratory volumes differ from each other. As a result, the interpretation of strain derived from $\mathrm{V}_{\mathrm{T}}$ divided by end-expiratory volume remains ambiguous. It is therefore preferable to consider these variables in isolation. In fact, by setting limits to $\mathrm{V}_{\mathrm{T}}$, PEEP, and $\mathrm{P}_{\text {plat }}$, prevailing ventilator management guidelines do just that.

\section{How Strain-Stress Informs the Interpretation of Clinical Trials and Recent Hypotheses of Ventilator-Induced Lung Injury}

As is widely known, a large multi-center clinical trial conducted by the ARDS Network (the ARMA trial) established a survival benefit in subjects with ARDS who were ventilated with low as opposed to high $\mathrm{V}_{\mathrm{T}}(6 \mathrm{~mL} / \mathrm{kg}$ vs $12 \mathrm{~mL} / \mathrm{kg}$ predicted body weight). ${ }^{11}$ Because $\mathrm{V}_{\mathrm{T}}$ is a critical determinant of strain (regardless of one's chosen definition), this finding is in keeping with biophysical injury mechanisms as they are currently understood. ${ }^{12,13}$ However, recall that a post hoc analysis that included
ARMA trial data suggested that $\Delta \mathrm{P}$ (and not $\mathrm{V}_{\mathrm{T}}$ ) was the variable that best stratified the biophysical lung injury risk of subjects with ARDS. ${ }^{6}$ At first glance, this may seem surprising because $\Delta \mathrm{P}$ and $\mathrm{V}_{\mathrm{T}}$ are interdependent: $\Delta \mathrm{P}=$ $V_{T} / C_{R S}$, where $C_{R S}$ is the compliance of the relaxed respiratory system (the stiffness term in Hooke's law). However, if confirmed, the post hoc analysis suggests that $\mathrm{V}_{\mathrm{T}}$-related injury risks vary with $\mathrm{C}_{\mathrm{RS}}$.

This hypothesis is attractive for 2 reasons. $C_{R S}$ is a marker of disease severity because $\mathrm{C}_{\mathrm{RS}}$ varies in proportion to the number of aerated and recruitable lung units (ie, of the size of Gattinoni's baby lung). ${ }^{13}$ Therefore, a low $\mathrm{C}_{\mathrm{RS}}$ not only identifies sicker patients with a worse prognosis, but also patients - who by virtue of having fewer recruitable alveoli-are more likely to suffer damage from alveolar overdistention.

A related reason why driving pressure may be superior to $\mathrm{V}_{\mathrm{T}}$ as initial guide for safe ventilator settings is the fact that normalizing or expressing $\mathrm{V}_{\mathrm{T}}$ as a function of predicted body weight, as was done in the ARMA trial, fails to take into account the effect of disease on available lung volume. The primary determinants of predictive body weight, namely gender and height, scale with the size of the normal, healthy lung, but not with that of the diseased lung. ${ }^{14}$

Since the recognition of ventilator-induced lung injury (VILI), researchers and clinicians have sought to identify a singular surrogate that could serve as marker of VILI risk and, therefore, act as a guide for individualizing care. Along these lines, Gattinoni and colleagues have recently proposed that the power (work per unit time) applied by the mechanical ventilator on the relaxed respiratory system may serve that purpose..$^{15}$ Although it is not overly difficult to measure work on the relaxed respiratory system (based on the 


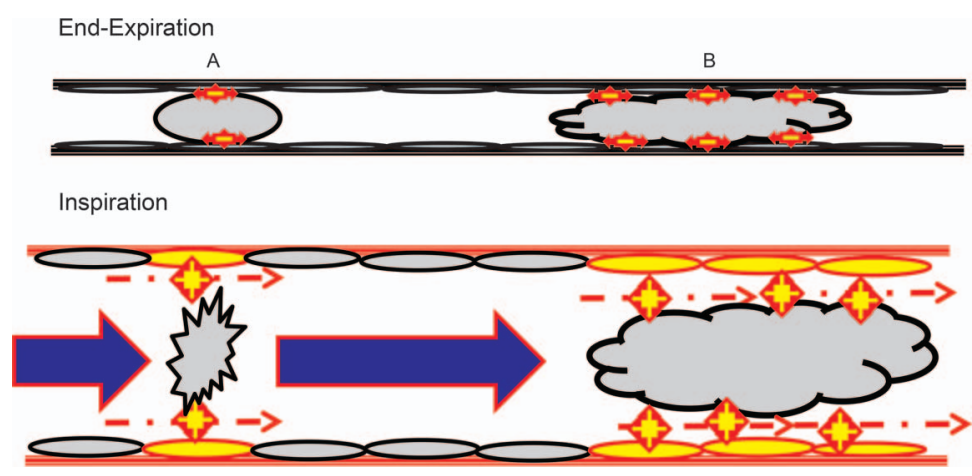

Fig. 3. Depiction of shear stress development from the breaking of liquid bridges (A) and liquid plugs (B) formed from pulmonary edema fluid in peripheral airways. The stars represent surface tension forces developed within the foam and plug that are transmitted to the surface of airway epithelium. During inspiration, as the foam menisci are broken and plugs are displaced distally, shear forces develop between the displaced liquid and the relatively stable epithelial cell membranes.

area of airway pressure volume loops), there is scant evidence to date in support of this hypothesis.

Skepticism about this hypothesis rests on the uncertainty that contributions of breathing frequency, flow, and $\mathrm{V}_{\mathrm{T}}$ to power transfer to the lungs may not scale with their respective contribution to injury risk. Moreover, the effects of PEEP on injury risk may not be sufficiently captured by this approach. While there is some evidence that breathing frequency influences certain manifestations of lung injury under specific experimental conditions, ${ }^{7}$ the many interactions between disease state and breathing frequency, driving pressure, pressure (stress) maxima and minima, and the rate of parenchymal deformation remain undefined.

\section{VILI, Biotrauma, and the Role of PEEP}

Even though driving pressure emerged as the single best predictor of biophysical injury risk (in post hoc analyses of large data sets), large pressure changes are unlikely to injure cells and tissues through a single mechanism. That is because mechanical ventilation with large driving pressures also affects vascular barrier properties, surfactant kinetics and function, and amplifies parenchymal stresses attributable to alveolar wall tension and interdependence effects. ${ }^{16}$

When viewed through the lens of cell and tissue micromechanics, injury manifests as a loss of epithelial and endothelial cell integrity that is accompanied by an influx of inflammatory cells. Stresses that wound epithelial cells tend to be interfacial in nature. They are caused by movement and/or rupture of liquid bridges and liquid plugs that cross the epithelial surface (Fig. 3). Thus, interventions designed to minimize air space fluid and plug formation are generally lung-protective. ${ }^{17}$

The clinical literature addresses these mechanisms in the context of alveolar recruitment, PEEP management, and the avoidance of atelectrauma. The original description of atelectrauma was based on experiments in unperfused, saline-lavaged rat lungs that were subjected to ex vivo mechanical ventilation. This model underscored the effects of airway and air-space liquid on epithelial integrity and thereby provided a rationale for the lung-protective effects of PEEP and for the salutary effects of fluid restriction in the management of patients with ARDS. ${ }^{18}$ By increasing end-expiratory lung volume and transalveolar pressure, PEEP reduces the probability of air-space occlusion by liquid bridges and promotes the translocation of edema fluid from air spaces to the interstitium. ${ }^{19}$

While there is ample evidence that PEEP is lung-protective in patients with ARDS, several large clinical trials have failed to identify a single "best" approach to PEEP management. ${ }^{20-23}$ Controversies and discordant results may be rooted in less than optimal patient selection criteria, in the choice of procedures and biomarkers used to guide PEEP dosing, and in uncertainty about untoward cardiovascular side effects and their management. The latter concern is true for virtually all clinical trials focused on lung protection and may well explain the apparent harm associated with high-frequency oscillatory mechanical ventilation in a recent study. ${ }^{24}$

Patients with ARDS are at risk for right heart failure, whereby aggressive recruitment efforts accompanied by high PEEP tend to increase that risk. ${ }^{25}$ The problem may not be recognized unless the patient becomes hypotensive or is examined using bedside ultrasonography. Faced with a hypotensive patient, the provider may choose to give intravenous fluids, add an inotrope, or reduce PEEP. These decisions are rarely if ever explicitly addressed in standard operating procedures of clinical trials, so it is unclear whether a fall in blood pressure by itself is a sufficiently sensitive or specific guide to appropriate cardiovascular management. 


\section{Understanding Pulmonary Stress-Strain In ARDS}

\section{Clinical Management Strategies}

In the absence of strong clinical evidence that would favor a specific approach to PEEP management, such management is typically guided by responses in gas-exchange or respiratory-system mechanics. Gas-exchange-based protocols adjust PEEP in relation to $\mathrm{F}_{\mathrm{IO}_{2}}$ as originally defined in the standard operating procedure of the ARDSnet trials. ${ }^{11}$ Compare to the version used in the original ARMA trial (the so-called low PEEP- $\mathrm{F}_{\mathrm{IO}_{2}}$ table), a more recent update has adopted a more aggressive recruitment strategy (high PEEP-F $\mathrm{IO}_{2}$ table). ${ }^{22}$ Protocols based on respiratory mechanics typically adjust PEEP with the goal to minimize $\Delta \mathrm{P} .{ }^{26}$ The rationale for this approach is that ventilating patients over the most compliant range of their respiratory system's pressure-volume relationship minimizes the respective injury risks associated with alveolar overdistention and cyclic recruitment. ${ }^{27}$

There is emerging interest in adjunct technologies including esophageal manometry, lung ultrasonography, and thoracic impedance plethysmography as guides for PEEP management. ${ }^{28,29}$ While the use of imaging technologies is largely confined to case series and observational studies, a small clinical trial suggested that esophageal-pressure-targeted PEEP management was superior to a gas-exchangebased algorithm. ${ }^{30}$ Notwithstanding concerns among physiologists and clinicians about the limiting assumptions of esophageal manometry in recumbent ARDS patients, a larger clinical trial that is to address the clinical efficacy of this technique is nearing completion. ${ }^{31}$

\section{Maximum Lung Stress and $\mathbf{P}_{\text {plat }}$}

As already discussed, the injury risk associated with repeated inflations of the lungs and respiratory system to high volumes and pressures depends greatly on the corresponding driving pressure. In the classic experiments of Webb and Tierney, ${ }^{32}$ rats were ventilated to peak pressures of $40 \mathrm{~cm} \mathrm{H}_{2} \mathrm{O}$. The lung-protective effect of reducing driving pressures (from 40 to $30 \mathrm{~cm} \mathrm{H}_{2} \mathrm{O}$ ) was attributed to a lung-protective effect of PEEP, which had been increased from 0 to $10 \mathrm{~cm} \mathrm{H}_{2} \mathrm{O}$. It stands to reason, however, that PEEP would not have been (as) protective if driving pressure had not been reduced as well. Needless to say, there is a maximum lung stress that should not be exceeded regardless of the associated driving pressure. Because maximum lung stress (ie, the elastic recoil pressure of the lung at end-inspiration) is rarely measured in clinical practice, most ventilator-management guidelines limit $\mathrm{P}_{\text {plat }}$ (ie, the elastic recoil pressure of the relaxed respiratory system at end-inflation) to $\leq 30 \mathrm{~cm} \mathrm{H}_{2} \mathrm{O}$.

This guideline is based on the assumption that the chest wall mechanical properties are normal so that the corresponding transpulmonary pressure will not exceed $20 \mathrm{~cm} \mathrm{H}_{2} \mathrm{O}$.
Critics of this assumption argue that this estimate was derived from esophageal pressure measurements in seated normal volunteers and therefore does not apply to recumbent patients, particularly those with obesity, ileus, or ascites. ${ }^{33}$ In such patients, the lung volume at end-expiration is substantially reduced and often requires PEEP settings between 15 and $20 \mathrm{~cm} \mathrm{H}_{2} \mathrm{O}$ simply to counterbalance the abdominal load. Limiting $\mathrm{P}_{\text {plat }}$ to $\leq 30 \mathrm{~cm} \mathrm{H}_{2} \mathrm{O}$ under those circumstances would make it impossible provide adequate alveolar ventilation.

\section{Unresolved Issues Surrounding VILI}

Despite significant advances in our understanding of the molecular determinants of mechanotransduction, related fundamental research has yet to generate clinically feasible and efficacious interventions targeting VILI risk reduction. ${ }^{34}$ Experimental VILI models, which generally cannot capture the full scope of patients' disease and healthcare exposures, tend to focus on early manifestations of injury such as edema and inflammation. In that context, immunosuppressive effects of pharmacologic and molecular interventions are generally deemed protective, even though it is unclear whether such responses are adaptive or maladaptive. The many unresolved questions surrounding fundamental biophysical mechanisms that shape the responses of injured lungs to deforming stress are beyond the scope of this clinical review.

While attention to $\mathrm{V}_{\mathrm{T}}$ and driving pressure have contributed to a decline in the incidence of health-care-acquired ARDS, there is a great deal of uncertainty about how to judge VILI risk in a given patient and, therefore, how best to individualize care. For example, some patients with ARDS, when supported in a pressure-pre-set mechanical ventilation mode, choose tidal volumes that exceed lung-protective guidelines. This occurs not infrequently after several days of mechanical ventilation and is thought to reflect the influence of prolonged sedative and narcotic use on respiratory drive and timing. ${ }^{35}$

In that instance, the provider must question if lung protection still mandates the imposition of low- $\mathrm{V}_{\mathrm{T}}$ mechanical ventilation, which would require a resumption of sedation and/or neuromuscular blockade, or if the VILI risk has decreased with time from the initial insult. While there are no clinical or experimental data that would speak to this issue, it could be argued that, in the subacute phase of ARDS, damage from interfacial stress is no longer of major concern because air-space fluid will have largely solidified. ${ }^{36}$ While there is no direct way to measure the mechanical properties of material filling air spaces in injured lungs, one may reasonably postulate that lungs filled with liquid are more recruitable than consolidated lungs.

Uncertainty about patient-specific VILI risk factors also dominates debates about indications and timing of intuba- 


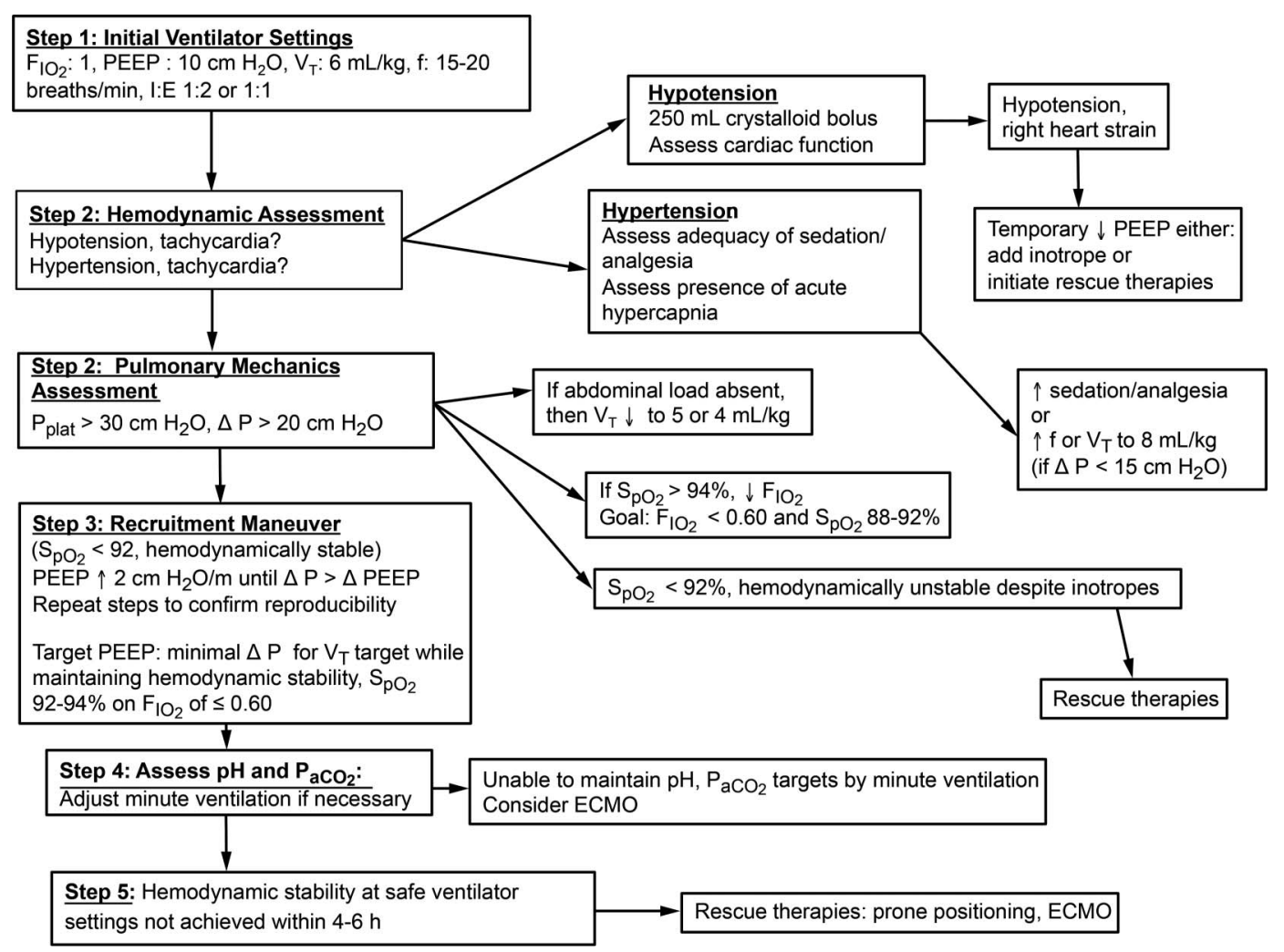

Fig. 4. Schematic representation of a pragmatic guide to safer ventilator management of unstable patients with severe lung injury. ECMO $=$ extracorporeal membrane oxygenation, Pplat $=$ plateau pressure.

tion and invasive mechanical ventilation, and about the use of rescue therapies such as extracorporeal membrane oxygenation (ECMO) and extracorporeal $\mathrm{CO}_{2}$ removal. While much of the VILI literature has focused on mechanical ventilation with high $\mathrm{V}_{\mathrm{T}}$ and low PEEP, there is reason to believe that spontaneous breathing would also produce injury as long as lung deformations are comparable between the modes of breathing. ${ }^{37}$

There is an emerging appreciation that excessive oxygen supplementation contributes to and amplifies lung deformation injury. ${ }^{38,39}$ Nevertheless, there is a great deal of uncertainty how to individualize $\mathrm{O}_{2}$ dosing. While most oxygen-titration guidelines target arterial oxygen saturations between $88 \%$ and $92 \%$, it is unclear if and how these targets should be modified in patients with metabolic or cardiovascular stress. Regardless, prolonged exposure (ie, days) to $\mathrm{F}_{\mathrm{IO}_{2}} \geq 0.80$ should be avoided and a safer goal would be a target of $\mathrm{F}_{\mathrm{IO}_{2}} \leq 0.60 .{ }^{39}$ Furthermore, there is no consensus on the relative risks and benefits of hypercapnia. ${ }^{40}$ Given the topographical heterogeneity of ventilation-perfusion ratios in patients with ARDS, there must be a corresponding heterogeneity in alveolar gas tensions and local $\mathrm{pH}$. Their effects on mechanotransduction and local immune responses remain largely unexplored.

\section{Practical Bedside Strategy for Implementing Lung-Protective Ventilation in Severe ARDS}

Based upon the above discussion of VILI and the profoundly altered chest mechanics in ARDS, the following algorithm can be applied specifically to patients with particularly severe presentations who are unstable and warrant hyperoxygenation, sedation, and neuromuscular blockade in conjunction with intubation (Fig. 4).

\section{Step \#1}

Set $\mathrm{F}_{\mathrm{IO}_{2}}$ to 1.0 , PEEP to $10 \mathrm{~cm} \mathrm{H}_{2} \mathrm{O}$ and initiate volumepre-set mechanical ventilation with $\mathrm{V}_{\mathrm{T}}=6 \mathrm{~mL} / \mathrm{kg}$ predicted body weight at a frequency of $15-20$ breaths/min and an inspiratory flow setting between 0.75 and $1 \mathrm{~L} / \mathrm{s}$ (targeting an initial I-E ratio between 1:2 and 1:1).

Rationale. Using a volume-pre-set mode with constant (square wave) inspiratory flow as an initial approach facilitates the assessment of respiratory mechanics (particularly the contribution of airways resistance) and recruitment effects in that mode. 


\section{Understanding Pulmonary Stress-Strain In ARDS}

\section{Step \#2}

Assess blood pressure (invasive measurement preferred), heart rate, $\mathrm{P}_{\text {plat }}, \Delta \mathrm{P}$, and arterial oxygen saturation via pulse oximetry $\left(\mathrm{S}_{\mathrm{pO}_{2}}\right)$.

a) If these variables are within tolerance limits, proceed to Step \#3.

b) If the patient has tachycardia, hypotension, and/or has substantial pulse-pressure variations, give an intravenous fluid bolus (eg, an initial $250 \mathrm{~mL}$ bolus of a balanced electrolyte solution) and assess cardiac function using a portable echocardiograph/ultrasound probe. If the exam shows right heart strain in a hypotensive patient, temporarily reduce PEEP, consider an inotrope, and initiate a rescue therapy (typically prone posture and/or ECMO).

c) If the patient is hypertensive, assess the level of sedation and evaluate for undertreated/unrecognized pain. Afterward, consideration can be given to raising minute volume as hypertension could be a response to acute hypercapnia. Raise minute volume either by increasing the frequency (30-35 breaths $/ \mathrm{min}$ ) or $\mathrm{V}_{\mathrm{T}}$ in steps to $7-8 \mathrm{~mL} / \mathrm{kg}$ predicted body weight (particularly if $\Delta \mathrm{P}$ is $<15 \mathrm{~cm} \mathrm{H}_{2} \mathrm{O}$ ), or some combination thereof.

d) If $\mathrm{P}_{\text {plat }}$ is $>30 \mathrm{~cm} \mathrm{H}_{2} \mathrm{O}$, indicating that the corresponding driving $\Delta \mathrm{P}$ is $>20 \mathrm{~cm} \mathrm{H}_{2} \mathrm{O}$, reduce $\mathrm{V}_{\mathrm{T}}$ in steps to $4-5 \mathrm{~mL} / \mathrm{kg}$ predicted body weight. In patients with large abdominal loads, exclude a spurious elevation of $\Delta \mathrm{P}$ on account of expiratory flow limitation, airway closure, and inadvertent PEEP.

e) If $\mathrm{S}_{\mathrm{pO}_{2}}$ is $<92 \%$ in the presence of hemodynamic stability, initiate recruitment efforts (as outlined in Step \#3). If $\mathrm{S}_{\mathrm{pO}_{2}}$ is $<92 \%$ in a hemodynamically unstable patient who fails to correct hypoxemia in response to hemodynamic support measures, proceed to rescue therapies.

f) If $\mathrm{S}_{\mathrm{pO}_{2}}$ is $>94 \%$, reduce $\mathrm{F}_{\mathrm{IO}_{2}}$ with the goal to at least temporarily target a $\mathrm{F}_{\mathrm{IO}_{2}}$ of $<0.80$ and an $\mathrm{S}_{\mathrm{pO}_{2}}$ of $88-92 \%$, and then proceed with recruitment efforts.

\section{Step \#3}

Increase PEEP by $2 \mathrm{~cm} \mathrm{H} \mathrm{H}_{2} \mathrm{O}$ and monitor the $\mathrm{S}_{\mathrm{pO}_{2}}, \mathrm{P}_{\text {plat }}$, $\Delta \mathrm{P}$, and hemodynamic response. Unless blood pressure falls, repeat PEEP increments every $30-60 \mathrm{~s}$ until $\Delta \mathrm{P}$ starts to rise by $\geq 2 \mathrm{~cm} \mathrm{H}_{2} \mathrm{O}$ (ie, the change in $\mathrm{P}_{\text {plat }}$ exceeds the change in PEEP by $\geq 2 \mathrm{~cm} \mathrm{H}_{2} \mathrm{O}$ ). Such a rise suggests that the lung is approaching its maximum volume, at which point further recruitment attempts could exceed parenchymal stress tolerance. Then reduce PEEP in increments of $2 \mathrm{~cm} \mathrm{H}_{2} \mathrm{O}$ until $\Delta \mathrm{P}$ returns to its minimum level.

Repeat this process several times until the response becomes reproducible. At that point, any PEEP setting compatible with minimum driving pressure (for a given $V_{T}$ ) may be chosen. Some practitioners may decide to choose the highest PEEP at which this condition is met, whereas others may choose the lowest corresponding value in patients with limited cardiovascular reserve.

Rationale. As already discussed, there are many acceptable ways to arrive at an acceptable PEEP setting. The approach suggested here is consistent with the stress-index philosophy and should facilitate further reductions in $\mathrm{F}_{\mathrm{IO}_{2}}$.

\section{Step \#4}

Check arterial blood gases primarily to assess $\mathrm{P}_{\mathrm{aCO}}$ and $\mathrm{pH}$ and adjust minute volumes accordingly. If that cannot be accomplished safely, consider ECMO or extracorporeal $\mathrm{CO}_{2}$ removal.

\section{Step \#5}

If the desired outcome (ie, hemodynamic stability at safe ventilator settings and $\mathrm{F}_{\mathrm{IO}_{2}} \leq 0.60$ ) cannot be achieved within 4-6 h, consider rescue therapies, foremost prone positioning and depending on availability ECMO.

\section{REFERENCES}

1. Loring SH, Topulos GP, Hubmayr RD. Transpulmonary pressure: the importance of precise definitions and limiting assumptions. Am J Respir Crit Care Med 2016;194(12):1452-1457.

2. Wilson TA. Nonuniform lung deformations. J Appl Physiol Respir Environ Exerc Physiol 1983;54(6):1443-1450.

3. Talmor D, Sarge T, O'Donnell CR, Ritz R, Malhotra A, Lisbon A, et al. Esophageal and transpulmonary pressures in acute respiratory failure. Crit Care Med 2006;34(5):1389-1394.

4. Mead J, Takishima T, Leith D. Stress distribution in lungs: a model of pulmonary elasticity. J Appl Physiol 1970;28(5):596-608.

5. Henderson WR, Chen L, Amato MB, Brochard LJ. Fifty years of research in ARDS. Respiratory mechanics in acute respiratory distress syndrome. Am J Respir Crit Care Med 2017;196(7):822-833.

6. Amato MB, Meade MO, Slutsky AS, Brochard L, Costa EL, Schoenfeld DA, et al. Driving pressure and survival in the acute respiratory distress syndrome. N Engl J Med 2015;372(8):747-755.

7. Hotchkiss JR, Jr., Blanch L, Murias G, Adams AB, Olson DA, Wangensteen OD, et al. Effects of decreased respiratory frequency on ventilator-induced lung injury. Am J Respir Crit Care Med 2000; 161(2 Pt 1):463-468.

8. Chiumello D, Carlesso E, Cadringher P, Caironi P, Valenza F, Polli $\mathrm{F}$, et al. Lung stress and strain during mechanical ventilation for acute respiratory distress syndrome. Am J Respir Crit Care Med 2008;178(4):346-355.

9. Brower RG, Hubmayr RD, Slutsky AS. Lung stress and strain in acute respiratory distress syndrome: good ideas for clinical management? Am J Respir Crit Care Med 2008;178(4):323-324.

10. Mattingley JS, Holets SR, Oeckler RA, Stroetz RW, Buck CF, Hubmayr RD. Sizing the lung of mechanically ventilated patients. Crit Care 2011;15(R:60):1-7.

11. ARDS Network, Brower RG, Matthay MA, Morris A, Schoenfeld D, Thompson BT, Wheeler A. Ventilation with lower tidal volumes as compared with traditional tidal volumes for acute lung injury and the acute respiratory distress syndrome. N Engl J Med 2000;342(18): 1301-1308. 


\section{Understanding Pulmonary Stress-Strain In ARDS}

12. Curley GF, Laffey JG, Zhang H, Slutsky AS. Biotrauma and ventilator-induced lung injury: clinical implications. Chest 2016;150(5): 1109-1117.

13. Gattinoni L, Pesenti A. The concept of "baby lung." Intensive Care Med 2005;31(6):776-784.

14. Crapo RO, Morris AH, Clayton PD, Nixon CR. Lung volumes in healthy nonsmoking adults. Bull Eur Physiopathol Respir 1982;18(3): 419-425.

15. Cressoni M, Gotti M, Chiurazzi C, Massari D, Algieri I, Amini M, et al. Mechanical power and development of ventilator-induced lung injury. Anesthesiology 2016;124(5):1100-1108.

16. Suki B, Hubmayr R. Epithelial and endothelial damage induced by mechanical ventilation modes. Curr Opin Crit Care 2014;20(1): 17-24.

17. Hussein O, Walters BJ, Stroetz RW, Valencia PA, McCall D, Hubmayr RD. Biophysical determinants of alveolar epithelial plasma membrane wounding associated with mechanical ventilation. Am J Physiol Lung Cell Mol Physiol 2013;305(7):L478-L484.

18. National Heart Lung and Blood Institute ARDS Clinical Trials Network, Wiedemann HP, Wheeler AP, Bernard GR, Thompson BT, et al. Comparison of two fluid-management strategies in acute lung injury. N Engl J Med 2006;354(24):2564-2575.

19. Malo J, Ali J, Wood LD. How does positive end-expiratory pressure reduce intrapulmonary shunt in canine pulmonary edema? J Appl Physiol Respir Environ Exerc Physiol 1984;57(4):1002-1010.

20. Briel M, Meade M, Mercat A, Brower RG, Talmor D, Walter SD, et al. Higher vs lower positive end-expiratory pressure in patients with acute lung injury and acute respiratory distress syndrome: systematic review and meta-analysis. JAMA 2010;303(9):865-873.

21. Mercat A, Richard JC, Vielle B, Jaber S, Osman D, Diehl JL, et al. Positive end-expiratory pressure setting in adults with acute lung injury and acute respiratory distress syndrome: a randomized controlled trial. JAMA 2008;299(6):646-655.

22. Brower RG, Lanken PN, MacIntyre N, Matthay MA, Morris A, Ancukiewicz M, et al. Higher versus lower positive end-expiratory pressures in patients with the acute respiratory distress syndrome. N Engl J Med 2004;351(4):327-336.

23. Meade MO, Cook DJ, Guyatt GH, Slutsky AS, Arabi YM, Cooper DJ, et al. Ventilation strategy using low tidal volumes, recruitment maneuvers, and high positive end-expiratory pressure for acute lung injury and acute respiratory distress syndrome: a randomized controlled trial. JAMA 2008;299(6):637-645.

24. Ferguson ND, Cook DJ, Guyatt GH, Mehta S, Hand L, Austin P, et al. High-frequency oscillation in early acute respiratory distress syndrome. N Engl J Med 2013;368(9):795-805.

25. Boissier F, Katsahian S, Razazi K, Thille AW, Roche-Campo F, Leon R, et al. Prevalence and prognosis of cor pulmonale during protective ventilation for acute respiratory distress syndrome. Intensive Care Med 2013;39(10):1725-1733.
26. Suter PM, Fairley B, Isenberg MD. Optimum end-expiratory airway pressure in patients with acute pulmonary failure. N Engl J Med 1975;292(6):284-289.

27. Protti A, Cressoni M, Santini A, Langer T, Mietto C, Febres D, et al. Lung stress and strain during mechanical ventilation: any safe threshold? Am J Respir Crit Care Med 2011;183(10):1354-1362.

28. Blankman P, Shono A, Hermans BJ, Wesselius T, Hasan D, Gommers D. Detection of optimal PEEP for equal distribution of tidal volume by volumetric capnography and electrical impedance tomography during decreasing levels of PEEP in post cardiac-surgery patients. Br J Anaesth 2016;116(6):862-869.

29. Mauri T, Yoshida T, Bellani G, Goligher EC, Carteaux G, Rittayamai N, et al. Esophageal and transpulmonary pressure in the clinical setting: meaning, usefulness and perspectives. Intensive Care Med 2016;42(9):1360-1373.

30. Talmor D, Sarge T, Malhotra A, O'Donnell CR, Ritz R, Lisbon A, et al. Mechanical ventilation guided by esophageal pressure in acute lung injury. N Engl J Med 2008;359(20):2095-2104.

31. Fish E, Novack V, Banner-Goodspeed VM, Sarge T, Loring S, Talmor D. The Esophageal Pressure-Guided Ventilation 2 (EPVent2) trial protocol: a multicentre, randomised clinical trial of mechanical ventilation guided by transpulmonary pressure. BMJ Open 2014; 4(9): $\mathrm{e} 006356$

32. Webb HH, Tierney DF. Experimental pulmonary edema due to intermittent positive pressure ventilation with high inflation pressures: protection by positive end-expiratory pressure. Am Rev Respir Dis 1974;110(5):556-565.

33. Behazin N, Jones SB, Cohen RI, Loring SH. Respiratory restriction and elevated pleural and esophageal pressures in morbid obesity. J Appl Physiol (1985) 2010;108(1):212-218.

34. Humphrey JD, Dufresne ER, Schwartz MA. Mechanotransduction and extracellular matrix homeostasis. Nat Rev Mol Cell Biol 2014; 15(12):802-812.

35. Seda G, Tsai S, Lee-Chiong T. Medication effects on sleep and breathing. Clin Chest Med 2014;35(3):557-569.

36. Thille AW, Esteban A, Fernandez-Segoviano P, Rodriguez JM, Aramburu JA, Vargas-Errazuriz P, et al. Chronology of histological lesions in acute respiratory distress syndrome with diffuse alveolar damage: a prospective cohort study of clinical autopsies. Lancet Respir Med 2013;1(5):395-401.

37. Brochard L, Slutsky A, Pesenti A. Mechanical ventilation to minimize progression of lung injury in acute respiratory failure. Am J Respir Crit Care Med 2017;195(4):438-442.

38. Girardis M, Busani S, Damiani E, Donati A, Rinaldi L, Marudi A, et al. Effect of conservative vs conventional oxygen therapy on mortality among patients in an intensive care unit: the oxygen-ICU randomized clinical trial. JAMA 2016;316(15):1583-1589.

39. Kallet RH, Matthay MA. Hyperoxic acute lung injury. Respir Care 2013;58(1):123-141.

40. Curley G, Laffey JG, Kavanagh BP. Bench-to-bedside review: carbon dioxide. Crit Care 2010;14(2):220. 